ORIGINAL ARTICLE

\title{
Endoscopic Repair of Cartilaginous Septal Perforation With Alloderm And Rotational Flap
}

\author{
Tarek Abdel-Moaty Omran ${ }^{1}$, Adly Ahmed Tantawy ${ }^{1}$, Ashraf El-Sayed El-Malt ${ }^{1}$ and Sufyan \\ Saed $\mathrm{Ali}^{2} *$ \\ ${ }^{1}$ Egypt, Zagazig University, Faculty of Medicine, Otorhinolaryngology Department \\ ${ }^{2}$ Libya, Tripoli University, Faculty of Medicine, Otorhinolaryngology Department
}

\section{*Corresponding Author : Name :Sufyan Saed Ali}

Email: sufiandwal@gmail.com

\begin{tabular}{|l|l|}
\hline Submit Date & $2019-04-29$ \\
\hline Revise Date & $2019-06-17$ \\
\hline Accept Date & $2019-06-22$ \\
\hline
\end{tabular}

\begin{abstract}
Background: Nasal septal perforation is an anatomical defect of the cartilaginous and/or bony nasal septum. There are many causes for septal perforaton including prior nasal surgery ,nasal trauma , cocaine abuse ,inflammatory disorders ,infection, cancer. The mechanical closure with a prosthesis such as the septal button. Silicon buttons can alleviate epistaxis, whistling and nasal obstruction, but these prostheses cannot control the production of crusting around the margins of the button which causes discomfort for patients. Objectives: the aim of this study was to evaluate endonasal endoscopic repair of cartilaginous nasal septal perforation. Patients and Methods: The study included 24 Patients; they were 16 males and 8 females, their age ranged from 18 to 53 years to 50 years underwent endoscopic repair for the perforation of cartilaginous septum with alloderm and rotational flap. Results: The study, showed that 23 cases had complete healing after endoscopy with success rate $(95.8 \%)$ and one case failed due to flap necrosis $(4.2 \%)$. Conclusions: Endoscopic repair for the perforation of cartilaginous septum with alloderm and rotational flap approach can be considered as an effective technique for septal perforation. The use of Alloderm, has the advantage of decreasing morbidity and suitable for all perforations sizes, acting as an excellent scaffold for re-epithelization, but is associated with high costs and the septal flap provide a good vascularity for good healing .
\end{abstract}

Keywords: Cartilaginous Septal Perforation; Alloderm; Rotational Flap

\section{INTRODUCTION}

T he perforation of nasal septum is considered an anatomical defect of the cartilaginous and/or the bony nasal septum. There are many causes for septal perforaton including prior nasal surgery, nasal trauma, cocaine abuse, inflammatory disorders and infection, cancer. In many cases it is asymptomatic, but when symptomatic patients have recurrent epistaxis, nasal crusting, whistling, headache, dryness, and nasal obstruction. Anterior perforations are generally symptomatic, while posterior ones are asymptomatic because the air is humidified by the mucosa of the nasal, and prevent dryness [1].

Only symptomatic perforations require treatment to relieve symptoms. Medical treatment with nasal irrigation and ointments can only reduce crusting, dryness and nasal obstruction in mild symptomatic perforations [2].

A useful alternative is mechanical closure with a prosthesis such as the septal button. Silicon buttons can alleviate epistaxis, whistling and nasal obstruction, but these prostheses cannot control the production of crusting around the margins of the button 
which causes discomfort for patients. New silicon buttons and magnet-based buttons reduce the patient's discomfort and crusting [3].

If these treatments are unsuccessful, surgical treatment is recommended. There are many reports discussed the surgical techniques for repairing the perforation of nasal septum, but mostly are difficult technically and need surgeons with high experience and are associated with a relatively low rate of success, as demonstrated by the high number of re-perforations[4] .

The aim of this study was to evaluate endonasal endoscopic repair of cartilaginous nasal septal perforation.

\section{PATIENTS AND METHODS}

This study was conducted in Otorhinolaryngology department, Faculty of Medicine, Zagazig University, over the period from April 2017 to January 2019 and included 24 patients with cartilaginous nasal septal perforation undergoing endoscopic repair of the perforation using alloderm combined with rotational flap.

Written informed consent was obtained from all participants and the study was approved by the research ethical committee of Faculty of Medicine, Zagazig University. The work has been carried out in accordance with The Code of Ethics of the World Medical Association (Declaration of Helsinki) for studies involving humans.

All patients subjected to Full history taking including personal history, Complete physical examination, nasal examination, Routine laboratory investigations, coagulation profile and Routine radiological study (Computed Tomography). The perforation size was measured at horizontal and vertical planes with a tape measure by using a $0^{\circ}$ endoscope, surgery was performed under general anaesthesia, topical nasal vasoconstrictor was applied -mention the name ,form and company of the product- then endoscopic nasal examination using 0 degree $4 \mathrm{~mm}$ endoscope was performed.

Anterior edge of the septum Curettage for a "freshening of the edge" effect and allows a small amount of bleeding the flap integration, the beginning of the superiorly based flap which with both mucoperichondrium and mucoperiosteum were marked by the appearance of posterior perforation by a Beaver knife we fashions the posterior flap border was vertically with the septum, posterior to the axilla septal projection of the middle turbinate by about 0.5 to $1.0 \mathrm{~cm}$., then continuing the incision along the floor of nose, after that, the incision turned to be parallel to the septum. The incision was perpendicular to the septum, to reach the perforation inferior border. The elevation of flap is necessary to decrease the mobility and blood supply for the flap, the flap rotation advancement, of the anterior ethmoidal artery was developed and don't we does not cover the perforation by a flap on the contralateral side. Rehydration of the freezedried alloderm for a minimum of 10 minutes in (normal Nacl 0.9) saline.

All patients in this study received the 2$\times 4-\mathrm{cm}$ thick implant Every sheet was cut for the shape correction according to anatomic requirement of the patients. The alloderm graft was inserted through the hemitrans fix incision in the tunnel between the elevated septal mucoperichondrium and the septal cartilage. The borders of Graft were positioned under the separated margins in underlay pattern for a $5 \mathrm{~mm}$ minimum around it (figure 1). The mucosal flap was carefully advanced for covering the graft and perforation, but the nasal floor and the posterior part of the septum were uncovered. Surgical and gel foam was applied on graft and flap, Silastic sheets were bilaterally inserted and kept in place to avoid postoperative scarring for 3 weeks. The cavities of the nasal were filled with sterile safratol then, removed after two days from surgery.

\section{Postoperative:}

Post-operatively, antibiotics were Intravenously given for three 3 days. Followed by oral antibiotic for five days, they were discharged 1 days postoperatively. After complete healing of the perforation, the Silastic sheets were removed, mostly during 2 to 3 weeks figure (2). follow-up was done 
monthly for three months figure (3), including perforation healing, crust, symptoms, reepithelium, and complications. The patients advised to stop smoking, kept away from noxious, fumes and dryness.

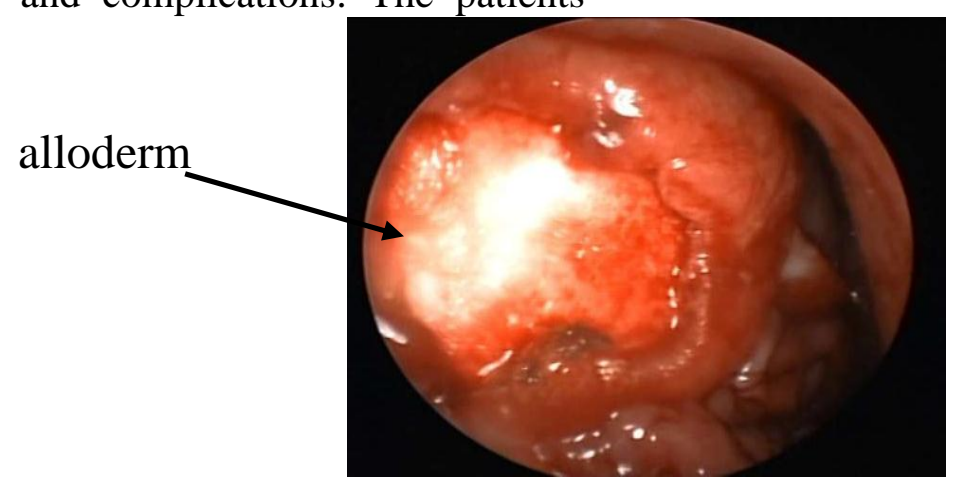

Figure (1) : insertion of alloderm graft

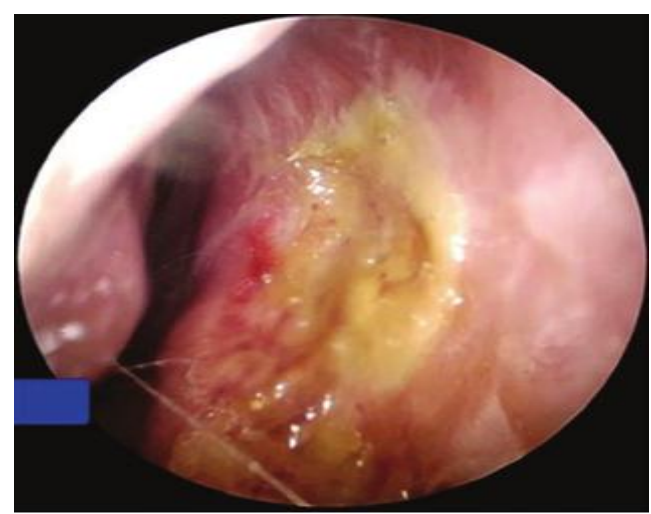

Figure (2) : 3weeks postoperative



Figure (3) : healed perforation 3 months postoperatively

\section{Statistical analysis}

Data were collected, tabulated and analyzed by SPSS 20, software for Windows. The significance level was set at $\mathrm{P}<0.05$.

\section{RESULTS}

This study included 24 cases undergoing endoscopic repair of cartilaginous septal perforation with alloderm and rotational flap from the outpatient clinic, ENT Department, Faculty of Medicine, Zagazig
University, the results is tabulated in the following tables.

Table (1), showed that the mean age of the study group was $(34.6 \pm 9.37)$ ranged from (18-53) years. Table (2), showed that the mean size of perforation in the study group was $(1.39 \pm 0.44)$ ranged from $(0.5$ to $1 \mathrm{~cm})$ in $25 \%$ of patients group and ranged from (1-2 $\mathrm{cm}$ ) in $75 \%$ of patients group. Table (3), showed the causes of septal perforation were 
Tarek A.. et al....

septal surgery (79.2\%), excessive cauterization $(16.7 \%)$ and blunt trauma $(4.2 \%)$. Table (4), showed that the most symptom were crusting (95.8\%), nasal obstruction (95.8), epistaxis (54.2\%). Table (5), showed that the success rate was $(95.8 \%)$ and one case failed due to flap necrosis $(4.2 \%)$.

Table (1): Socio-demographic characteristics of the study group:

\begin{tabular}{|c|c|c|}
\hline Variable & \multicolumn{2}{|c|}{ case group (24) } \\
\hline $\begin{array}{l}\text { Age (years): } \\
\text { mean } \pm \text { SD } \\
\text { (Range) } \\
\text { median }\end{array}$ & \multicolumn{2}{|c|}{$\begin{array}{c}34.6 \pm 9.37 \\
(18-53) \\
35\end{array}$} \\
\hline & NO & $\%$ \\
\hline $\begin{array}{l}\text { Sex } \\
\text { Male } \\
\text { Female }\end{array}$ & $\begin{array}{c}16 \\
8\end{array}$ & $\begin{array}{l}66.7 \% \\
33.3 \%\end{array}$ \\
\hline
\end{tabular}

Table (2): Perforation size in the study group:

\begin{tabular}{|c|c|c|}
\hline Variable & \multicolumn{2}{|c|}{ The case group (24) } \\
\hline $\begin{array}{l}\text { perforation size }(\mathrm{mm}): \\
\text { mean } \pm \text { SD } \\
(\text { Range }) \\
\text { Median }\end{array}$ & & \\
\hline Variable & NO & $\%$ \\
\hline $\begin{array}{l}\text { perforation size } \\
0.5-1 \mathrm{~cm} \\
1-2 \mathrm{~cm}\end{array}$ & $\begin{array}{c}6 \\
18\end{array}$ & $\begin{array}{l}25.0 \% \\
75.0 \%\end{array}$ \\
\hline
\end{tabular}

Table (3): Causes of septal perforation:

\begin{tabular}{|l|c|c|}
\hline Variable & NO(24) & $\%$ \\
\hline Septal surgery & 19 & $79.2 \%$ \\
Excessive cauterization & 4 & $16.7 \%$ \\
Blunt trauma & 1 & $4.2 \%$ \\
\hline
\end{tabular}

Table (4): Symptoms of nasal perforation:

\begin{tabular}{|l|c|c|}
\hline Symptoms & NO (24) & $\%$ \\
\hline Crusting & 23 & $95.8 \%$ \\
Nasal obstruction & 23 & $95.8 \%$ \\
Epistaxis & 13 & $54.2 \%$ \\
Pain & 1 & $4.2 \%$ \\
Whistling & 1 & $4.2 \%$ \\
Headache & 1 & $4.2 \%$ \\
Nasal discharge & 1 & $4.2 \%$ \\
\hline
\end{tabular}


Table (5): Success rate in the study group:

\begin{tabular}{|l|c|c|}
\hline Success rate & NO(24) & $\%$ \\
\hline Successes cases & & \\
Failed cases & 23 & $95.8 \%$ \\
& 1 & $4.2 \%$ \\
\hline
\end{tabular}

\section{DISCUSSION}

The trend of septal perforation repair techniques has completely changed in the last three decades: from 1986 to 1996 an open approach (open rhinoplasty, midfacial degloving, etc.) was the favorite approach with just three publications about a closed approach. In the decade 1996-2006, open and closed approaches had the same numbers of publications and an endoscopic approach began to be described. In the last decade, closed approaches were prominent, together with a large number of publications on endoscopic approaches [3]. There many advantages for the closed approach) such as decreasing invasiveness (without external scars), and good perforation margins control. The drawbacks that it takes a long time and sometimes performance be difficult, and need high experience [3].

In our study the mean size of perforation was $(1.39 \pm 0.44)$ ranged from $(0.5$ to $1 \mathrm{~cm})$ in $25 \%$ of patients group and ranged from (1-2 $\mathrm{cm})$ in $75 \%$ of patients group, which agree with study of Tastan et al. [5] and Cassano [6] who used endoscopic techniques in smallto-medium perforations $(0.5-2 \mathrm{~cm})$, but some report good results even in repair of perforations $>2 \mathrm{~cm}$. [1,5]

Septal surgery was the commonest cause of septal perforation $(79.2 \%)$ in our study followed by excessive cauterization $(16.7 \%)$ and lastly blunt trauma (4.2\%). Our results are in agree with lee et al. [6] who found that septoplasty $(85.8 \%)$ was the commonest cause of nasal septal perforation followed by cauterization $(7.1 \%)$ and finally idiopathic causes $(7.1 \%)$.

In our study the commonest symptom in the case group was crusting $(95.8 \%)$ and nasal obstruction (95.8) followed by epistaxis $(54.2 \%)$ and other symptoms like whistling, pain, , headache and nasal discharge, each of them was in $(4.2 \%)$ of the case group which inconsistent with the study of lee et al. [6]who found that the commonest symptom of nasal perforation was nasal obstruction (85.7\%), headache (21.4\%), whistling $(21.4 \%)$, epistaxis $(14.3 \%)$ and crusting (7.1\%).

In our study we used an acellular human dermal allograft (alloderm) and septal flap based on anterior ethmoidal artery on twenty four cases and we achieved success rate $(95.8 \%)$ with complete healing in twenty three cases and one case failed due to flap necrosis $(4.2 \%)$ which inconsistent with the study of Ayshford et al. [2] who found that the endoscopic repair with an acellular human dermal allograft (alloderm) and an anteriorly based inferior turbinate flap, achieved successful closure of the perforation with rate of $(76.5 \%)[2]$.

Castelnuovo et al. [7]reported that the use of an endoscopic approach has allowed very high percentage of success for nasal perforation repair with only an anterior ethmoidal artery unilateral septal flap without any interposition graft. Also Mansour [8]found that the unilateral nasal flap has the advantage of avoiding enlargement of the perforation and development of any other perforations during the operation. These results were in agreement of our result where the success rate $(95.8 \%)$ and one case failed due to flap necrosis $(4.2 \%)$.

Conclusions: Endoscopic repair for the perforation of cartilaginous septum with alloderm and rotational flap approach can be considered as an effective technique for septal perforation. The use of Alloderm, has the advantage of decreasing morbidity and suitable for all perforations sizes, acting as an excellent scaffold for re-epithelization, but is 
associated with high costs and the septal flap provide a good vascularity for good healing .

\section{REFERENCES}

1- Cassano M. Endoscopic repair of nasal septal perforation with "slide and patch" technique. Otolaryngol Head Neck Surg 2014 ;151:176-8.

2- Ayshford CA, Shykhon M, Uppal HS and Wake $\mathbf{M}$.Endoscopic repair of nasal septal perforation with acellular human dermal allograft and an inferior turbinate flap. Clin Otolaryngol Allied Sci 2003 ;28:29-33.

3- Cassano M. Endoscopic repair of nasal septal perforation. Acta Otorhinolaryngol Ital 2017:37 (6): 86-492.

4- Dosen LK and Haye R. Surgical closure of nasal septal perforation. Early and long term observations. Rhinology 2011;49:486-491.
5- Tastan E, Aydogan F, Aydin E, Can IH, Demirci M, Uzunkulaoglu $H$ et al. Inferior turbinate composite graft for repair of nasal septal perforation. Am J Rhinol Allergy 2012;26:237-42.

6- Lee HR, Ahn DB, Park JH, Kim YH, Sin CM, Sung-Jae Youn et al. Endoscopic repairment of septal perforation with using a unilateral nasal mucosal flap. Clin Exp Otorhinolaryngol 2008; 1 :154-7.

7- Castelnuovo P, Ferreli F, Khodaei I and Palma P. Anterior ethmoidal artery septal flap for the management of septal perforation. Arch Facial Plast Surg 2011;13:411-4.

8- Mansour HA. Repair of nasal septal perforation using inferior turbinate graft. J Laryngol Otol 2011; $125: 474-8$.

dwal, S., Omran, T., Tantawy, A., El-Malt, A. Endoscopic Repair of Cartilaginous Septal Perforation With Alloderm And Rotational Flap. Zagazig University Medical Journal, 2019; Jully. 2020 Volume 26 Issue 4 (598-603): -. doi: 10.21608/zumj.2019.12362.1217 